\title{
EFFECTIVENESS OF MANUAL THERAPY IN COCCYDYNIA: A CASE REPORT
}

\author{
Samina Ghulam*, Amjad Sharif.
}

Physiotherapist, Armed Forces Institute of Rabilitation Medicine, Rwawalpindi, Pakistan.

\section{ABSTRACT}

Introduction: Coccydynia is a painful disorder of the end portion of vertebral column. This is a relatively unusual condition with no universally accepted treatment. Patients with coccydynia should be managed conservative; conservative treatments include NSAIDs, local steroid injections, physiotherapy and precautions. Surgery can offer when failure of conservative treatment.

Case Description: A 28 years old female with chronic coccxydynia for two years after carrying a child, she had gone through physiotherapy, NSAIDs, and local steroids repeatedly. She was advised for coccygectomy. Her married and social life was extremely disturbed.

Procedure: Procedure of soft tissue mobilization (myofascial release) for pain management and sacrococcygeal joint mobilization was adopted to resume the mobility of joint.

Result: Before procedure, Score of Oswestry disability index was 38\% that showed moderate disability, pain level on VAS was $6 / 10$ and after treatment remarkable change in symptoms, Score of Oswestry disability index was $2 \%$ that showed minimal disability, pain level on VAS was $0 / 10$

Purpose: This case report describes the successful management of chronic coccydynia by sacrococcygeal joint mobilization and soft tissue release. This report will also help clinician to select appropriate manual therapy measure and avoid unnecessary use of other techniques and therapies. It also will avoid the hesitation in application of maneuver.

Recommendation: The further research and clinical trials are needed to explore selection of manual therapy procedures in term of their effectiveness on patients with chronic coccydynia.

KEY WORDS: Coccydynia, Manual Therapy, Myofascial Release, Sacrococcxygeal Mobilization, Coccygectomy.

Address for correspondence: Samina Ghulam, Physiotherapist, Armed Forces Institute of Rabilitation Medicine, Rwawalpindi, Pakistan E-Mail: Saminaghulam.sg@gmail.com

\begin{tabular}{|l|l|}
\hline \multicolumn{3}{|c|}{ Access this Article online } \\
\hline Quick Response code & \multicolumn{1}{|c|}{ International Journal of Physiotherapy and Research } \\
ISSN 2321- 1822
\end{tabular}

\section{INTRODUCTION}

Coccydynia means "tail bone pain [1-3]". It is first presented by simpson in $19^{\text {th }}$ century $[4,5]$. Coccydynia is rare painful disorder and aggravated by pressure $[3,6]$. This disorder can be manifested at any age but most common age is 40 years, ratio between male and female is 1:5(3, 4, 7). The well known risk factors of coccydynia are obesity, coccygeal sitting, child birth,constipation, tumor, infection, any direct trauma and it can be idiopathic c1 $[3,4,7]$.

Coccydynia is often associated with a difficult delivery $[2,3,8]$. Pain usually caused by altered mechanics of coccyx like hypomobility, hypermobility or subluxation $[3,9]$. Patients with coccyx pain usually complains pain associated with sitting aggravated after rising from seat, during defecation and sexual intercourse $[3,6,7,9]$. There is no particular standard for diagnosis of this disorder; however, coccyx 
mobility examination, pain provocation testing and radiographs have been proposed as reasonable diagnostic approaches $[1,2,10]$. In physical examination, palpation and manipulation of coccyx elicit the pain(10). The management of coccxydynia can be conservative and surgical. Patients with coccydynia should be managed conservatively; conservative treatments include NSAIDs, local steroid injections, physiotherapy and precautions. Surgery can offer when failure of conservative treatment $[1,3-6,11]$.

The indication and advantages of manual therapy are not perfectly reported yet [12], because of lack of expertise and existence of variety of management [12]. Radiographs of the coccyx in different positions divide the coccydynia into four etiologic groups according to coccygeal mobility: subluxation, hypermobility, hypomobility, and normal mobility [11,13]. These groups may show different response to manual treatments. It is evaluated that massage of soft tissue and sacrococcygeal joint mobilization are initial treatment for management of chronic coccxydynia [1,11].

Manual therapy consist of variety of techniques [12]. This case report describes the successful management of chronic coccydynia by sacrococcygeal joint mobilization and soft tissue release; it will establish evidence of particular external manual therapy technique for management of coccydynia because of hypomobile coccyx. This report will also help to physiotherapist to select appropriate manual therapy measure and avoid unnecessary use of other techniques and therapies. It also will avoid the hesitation in application of maneuver. The immediate selection of suitable therapy will reduce the disability and improve the quality of life.

Description of case: This case report followed a patient with chronic coccydynia from onset of symptoms after carrying a child with prolonged and difficult labors, two years back. The outcomes of the assessment, including history of illness, treatment and follow up, by use of Oswestry modified questionnaire and visual analogue scales, is being presented

History: Mrs. M 28 years old, house wife, has significant pain around coccyx for 2 years after carrying child, she is on naproxen daily dose, attended physiotherapy sessions six times in two years but not got complete relief and recurrence is frequent, had taken local steroid thrice in two years. She was advised for coccygectomy.

Examination: There is no particular/special test to confirm coccxydynia, external examination reported sharp pain on palpation, local tenderness around coccyx, hypomobility of sacrococcxygeal joint. The per rectal examination not done because it is invasive [10].

Investigation: Nothing significant in laboratory tests, X.ray revealed no change in of angle coccyx bone in standing and sitting, it confirms the hypomobility of joint

Consent: After examination, I explained my findings, procedure and purpose of procedure. I also asked permission, she signed the consent.

Pre-management score: Score of Oswestry disability index was $38 \%$ that showed moderate disability, pain level on VAS was $6 / 10$

Treatment

Patient position: Patient is on right side lying, knees fully bent on chest, head is in forward flexion.

Procedure: I placed my glove thumb between anus and tip of coccyx, approach the anterior surface of coccyx and I slide my finger cephalocaudal with slight pressure to mobilize the anterior soft tissue, initially, in first few seconds it was painful after 30 seconds patient became comfortable.

I continued this gentle movement with lateral medial sliding of thumb with slight pressure further 30 seconds (myofascial release); patient reported no pain on palpation.

After soft tissue mobilization, I performed sacrococcygeal joint mobilization to resume the mobility of joint. Patient was in above mentioned position I grasped coccyx between my thumb and index finger ( by placing thumb in space between anus and upper coccyx). I applied slight traction on coccyx and glide the coccyx anterior and posterior 5 times, performed three sets of same movement, first set was quite painful, $2^{\text {nd }}$ set was quite comfortable and third set was pain free. I gave three treatment sessions on alternate days.

Patient was also guided to perform sit bath and Kegel exercises twice a day. 
Post management score: Score of Oswestry disability index was $2 \%$ that showed moderate disability, pain level on VAS was $0 / 10$.

Follow up: Follow up performed after four weeks and three months after treatment, VAS was $0 /$ 10 and Oswestry score was $0 \%$.

\section{DISCUSSION}

Coccydynia is rare but painful condition, characterized by axial coccygeal pain which is usually aggravated by pressure (6). Many cases of coccxygeal pain have no identifiable cause, and conservative management includes NSAIDS, physiotherapy, local corticosteroids and intra rectal manipulation $(1,6,7,12)$. Manual therapy is non- surgical type of conservative management, Manual therapy has been widely practiced for centuries in many parts of the world to treat different musculoskeletal conditions including spinal disorders $[11,12]$. A pilot study was done by Jean-Yves Maigne, MD, ${ }^{*}$ and Gilles Chatellier, MD stated that overall effectiveness of manual therapy was poor [11]. Dr JY Maigne found a mild effectiveness approx $25 \%$ with trial treatment sessions intra rectal manipulation in chronic coccydynia in his 2006 report.

Our case report demonstrated a significant and an immediate relief of pain for chronic coccydynia. After three months of follow up, our patient has significant pain relief. In best of my knowledge our case report is different from previous studies, I used two manual therapy procedures, myofascial release for pain management and joint mobilization for stiffness for chronic coccydynia, and it not only improves pain but also improves quality of life of patient. It put away patient from coccygectomy. Inter rectal manipulation is an invasive technique, it may irritates the rectal lining [10].

This report describes the successful and appropriate clinical tool for management of chronic coccydynia. This case report improves the application of manual therapy by decreasing the hesitation of clinician to apply external manual procedures.

The report finding suggests that sacrococcxygeal joint mobilization and myofascial release should be offered to patients with hypomobile coccyx. We also suggest to clinician not to push the procedure to someone else who is not ready for
The further research and clinical trials are needed to explore, selection of manual therapy procedures in term of their effectiveness on patients with chronic coccxydynia.

\section{Conflicts of interest: None \\ REFERENCES}

[1]. Marinko LN, Pecci M. Clinical decision making for the evaluation and management of coccydynia: 2 case reports. journal of orthopaedic \& sports physical therapy. 2014;44(8):615-21.

[2]. Ryder I, Alexander J. Coccydynia: a woman's tail. Midwifery. 2000;16(2):155-60.

[3]. Howard PD, Dolan AN, Falco AN, Holland BM, Wilkinson CF, Zink AM. A comparison of conservative interventions and their effectiveness for coccydynia: a systematic review. Journal of Manual \& Manipulative Therapy. 2013;21(4):213-9.

[4]. Lirette LS, Chaiban G, Tolba R, Eissa H. Coccydynia: an overview of the anatomy, etiology, and treatment of coccyx pain. The Ochsner Journal. 2014;14(1):847.

[5]. Ravi Patel AA, and Peter G. Whangcorresponding author. Coccydynia. Musculoskeletal Med. Dec. 2008;1 (3-4).

[6]. Mitra R, Cheung L, Perry P. Efficacy of fluoroscopically guided steroid injections in the management of coccydynia. Pain Physician. 2007;10(6):775.

[7]. Hodges SD, Eck JC, Humphreys SC. A treatment and outcomes analysis of patients with coccydynia. The Spine Journal. 2004;4(2):138-40.

[8]. Maigne J, Rusakiewicz F, Diouf M. Postpartum coccydynia: a case series study of 57 women. European journal of physical and rehabilitation medicine. 2012;48(3):387-92.

[9]. Maigne J, Pigeau I, Aguer N, Doursounian L, Chatellier G. Chronic coccydynia in adolescents. A series of 53 patients. European journal of physical and rehabilitation medicine. 2011;47(2):245-51.

[10]. Marc Heller D. The Coccyx Revisited: External and Internal Exam Correction Procedures. Dynamic Chiropractic. Feb. 12, 2004. .

[11]. Maigne J-Y, Chatellier G. Comparison of three manual coccydynia treatments: a pilot study. Spine. 2001;26(20):E479-E83.

[12]. Sutcliffe P, Clar C, Tsertsvadze A, Briscoe S, Clarke A. Clinical and cost-effectiveness of manual therapy for the management of a variety of musculoskeletal and non-musculoskeletal conditions: a systematic review and narrative synthesis. Coventry, UK: Warwick Medical School; 2013.

[13]. Bronfort G, Haas M, Evans R, Leininger B, Triano J. Effectiveness of manual therapies: the UK evidence report. Chiropractic \& Manual Therapies. 2010;18(1):3.

How to cite this article: Samina Ghulam , Amjad Sharif. EFFECTIVENESS OF MANUAL THERAPY IN COCCYDYNIA: A CASE REPORT. Int J Physiother Res 2017;5(3):2010-2012. DOI: $10.16965 /$ ijpr.2017.116 